\title{
Response of kelps from different latitudes to consecutive heat shock.
}

Tânia R. PEREIRA ${ }^{a, b}$, Aschwin H. ENGELEN ${ }^{a}$, Gareth A. PEARSON ${ }^{a}$, Myriam VALERO $^{b}$, Ester A. SERRÃOa

(a) CCMAR, CIMAR - Laboratório associado, Faculdade de Ciências e Tecnologia, Universidade do Algarve, Gambelas, 8005-139 Faro, Portugal. Fax.: +351289800069; pereirataniar@gmail.com; aengelen@ualg.pt; gpearson@ualg.pt; eserrao@ualg.pt

(b) Centre National de la Recherche Scientifique, Université Paris 6 - Pierre et Marie Curie, UMR 7144, Equipe Biologie Evolutive et Diversité Marine BEDIM, Station Biologique de Roscoff, Place Georges Teissier, 29682 Roscoff Cedex, France; valero@sb-roscoff.fr

\section{Corresponding author}

Tânia R. Pereira

Postal address: CCMAR, CIMAR - Laboratório Associado, Universidade do Algarve, Campus de Gambelas, 8005-139 Faro, Portugal

Email: pereirataniar@gmail.com

Phone: +351916464712

\section{Abstract}

Although extensive work has focused on kelp responses to constant temperature, little is known about their response to the consecutive temperature shocks they are often exposed to in the shallow subtidal and intertidal pools. Here we characterized the responses of the two southernmost forest-forming kelp species in the Northeast Atlantic, Laminaria ochroleuca De 
La Pylaie and Saccorhiza polyschides (Lightf.) Batt. to multiple cycles of thermal stress. Individuals from the upper vertical limit of the geographical distribution edges where the two species co-occur forming forests, France and Portugal, were exposed to 4 consecutive cycles of thermal shock simulating a spring tide. A $24 \mathrm{~h}$ cycle consisted of culture at $15^{\circ} \mathrm{C}$, plus $1 \mathrm{~h}$ heat shock at one of five levels $\left(20,22.5,25,27.5\right.$ or $\left.30^{\circ} \mathrm{C}\right)$. The maximum quantum yield $(\mathrm{Fv} / \mathrm{Fm})$ of chlorophyll fluorescence of photosystem 2 (PS2) was used to detect impaired reaction centre function, as a proxy for individual fitness costs, during recovery from heat shock. Both species showed resilience to temperatures from 20 to $25{ }^{\circ} \mathrm{C}$. While exposure to $27.5^{\circ} \mathrm{C}$ caused no inhibition to $\mathrm{Fv} / \mathrm{Fm}$ of $\mathrm{S}$. polyschides, a threshold was met above this temperature and exposure to $30^{\circ} \mathrm{C}$ caused the death of all individuals. In contrast, L. ochroleuca from France was damaged but able to survive $30{ }^{\circ} \mathrm{C}$ shocks and individuals from Portugal showed complete resilience to this treatment. In both species, blade elongation decreased with increasing temperature, with necrosis surpassing growth at higher temperatures. Resilience to high temperature exposure may confer an advantage to L. ochroleuca to colonize intertidal pools on the Portuguese coast, in agreement with the observation that both species recruit in tide pools but only L. ochroleuca reach adulthood. Our results indicate that as summer temperatures increase with climate change, the disappearance of $S$. polyschides from intertidal pools and a decrease in the density of $L$. ochroleuca can be expected.

Keywords: Saccorhiza polyschides, Laminaria ochroleuca, chlorophyll fluorescence, heat-shock

\section{Introduction}

Temperature is a major factor influencing species geographical distribution, and has increased over the last decades due to anthropogenic pressure (Hampe and Petit, 2005; IPCC, 2007). Since 1980 , mean sea surface temperature increased $0.2-0.3^{\circ} \mathrm{C}$ per decade in southern 
Europe, and $0.3-0.7{ }^{\circ} \mathrm{C}$ in the Norwegian and North seas (Lima and Wethey, 2012). Moreover, projections indicate that warming rates may increase further in the coming decades (IPCC, 2007). These changes have the potential to cause local extinctions and poleward distribution shifts for several species (Hampe and Petit, 2005; Hiscock et al., 2004; Wernberg et al., 2010), as has been observed for several species of plankton (Beaugrand and Reid, 2003), gastropods (Mieszkowska et al., 2006), fish (Sabatés et al., 2006) and macroalgae (Nicastro et al., 2013), including kelps (Díez et al.,2012; Fernández 2011; Müller et al., 2009; Tuya et al., 2012; Voerman et al., 2013). However, just as terrestrial species' distribution shifts often occur in altitude (Franco et al., 2006; Kelly and Goulden, 2000), on marine shores the effects of climate change may be first observed in local species distribution on the shore, before geographical shifts are perceived (Cheung et al., 2009; Pehlke and Bartsch, 2008). Species populating shallower areas such as the intertidal and upper subtidal will be the first to experience the effects of global warming, as they're more exposed to temperature extremes, UV and excessive light, desiccation and osmotic stresses, and are more exposed to storm-induced wave surge. Indeed, intertidal species have been reported to suffer shifts in their geographical distribution faster than most terrestrial species (Helmuth et al., 2002). To persist as extreme environmental conditions become more frequent, populations will have to adjust to the new conditions and compensate for the elevated losses typical of populations near distributional boundaries (Guo et al., 2005). As such, the resilience of recruits and early stages to repeated cycles of heat shock is likely to be a determining factor in persistence of populations in the intertidal.

Kelps are habitat structuring species. They modify the area they populate, its environment and resources, and are fundamental for the survival of several other species (Bruno et al., 2003; Wernberg et al., 2010). Thus, variations in kelp species composition, size and canopy density will impact ecological and oceanographic processes. Although extensive work has been done on the temperature limits of kelp species (Bolton and Lüning, 1982; Fortes and Lüning, 1990; Izquierdo et al., 2002; Pang et al., 2007; Pereira et al., 2011; tom Dieck, 
1993), nothing is yet is known about their ability to cope with consecutive cycles of stress exposure associated with low tides. In this study, we aimed to recreate the conditions experienced by recruiting individuals during typical summer spring tides, where individuals may be exposed daily to repeated cycles of thermal stress during low tides, and which may be decisive for population persistence. Experiments were performed to compare the two southernmost kelp-forest species in the Northeast Atlantic: Laminaria ochroleuca and Saccorhiza polyschides. Since, as reported for several species of animals and plants, individuals from different latitudes may be locally adapted or acclimated to different conditions (Liu and Pang, 2010; Zippay et al., 2010), we compared the responses of individuals from the higher and lower latitude ranges where these two species coexist: Brittany, France and Northern Portugal. The results of such experiments can provide clues as to whether temperature is likely to be a decisive factor influencing the distribution, persistence and composition of these populations in the near future.

\section{Material and methods}

\subsection{Model species and collection}

L. ochroleuca and S. polyschides, a perennial and an annual species, respectively, are two important Northeast Atlantic species. They both have their southernmost populations in isolated spots in the upwelling region of west Morocco and some very deep areas in the Mediterranean and Atlantic seamounts and islets, south of their coastal distributional range which ranges from the Portuguese coast to Brittany (France), and the English and Bristol Channels (Birkett et al.,1998; Braud, 1974; Lüning, 1990; Norton, 1977; Titley and Neto, 2000; van den Hoek, 1982). S. polyschides has a wider northern distribution, found as far north as the west coast of Norway. 
Sporophytes of the two species have similar upper temperature limit of around $24{ }^{\circ} \mathrm{C}$ (Birkett et al., 1998; Norton, 1977). Although no records of lower temperature limits were found for either species, at their northern distribution limit average winter sea surface temperatures (SST) are $4{ }^{\circ} \mathrm{C}$ and $10{ }^{\circ} \mathrm{C}$, for S. polyschides and L. ochroleuca respectively (Braud, 1974; Norton, 1977). Moreover, these two species have an overlapping range of optimum temperatures. L. ochroleuca is described as growing better between 15 and $18{ }^{\circ} \mathrm{C}$, while $\mathrm{S}$. polyschides seems to perform better at temperatures from 10 to $17^{\circ} \mathrm{C}$ (Biskup et al., 2014, Izquierdo et al., 2002; Norton, 1977). As such, despite their distinct life strategies, the two species have overlapping niches and are potential competitors.

This study is focused on the distributional range where the two species overlap, from northwest Iberia to the English Channel. Recruits of L. ochroleuca and S. polyschides ca. $15 \mathrm{~cm}$ length were collected near the northern distribution limit of L. ochroleuca, in Brittany, France $\left(48^{\circ} 41^{\prime} 55.26^{\prime \prime} \mathrm{N} 3^{\circ} 56^{\prime} 28.50^{\prime \prime} \mathrm{W}\right)$, and in Northern Portugal $\left(41^{\circ} 42^{\prime} 27.80^{\prime \prime} \mathrm{N} 8^{\circ} 51^{\prime} 45.30^{\prime \prime} \mathrm{W}\right)$, the southern distribution limit where both species are able to form forests. In Brittany, the vertical distribution of both species extends as high as the upper subtidal, being out of water only during the lowest spring tides of the year. In Northern Portugal they can be found in tidal pools and although their base is usually immersed, their blades may get exposed during spring tides. In both areas, collections were made in the upper distribution limit and were transported in cold seawater inside refrigerated boxes. In Brittany, samples were collected on the $13^{\text {th }}$ of July 2011, arriving in the lab within 48h of collection. In Northern Portugal, collections were made on the $29^{\text {th }}$ of March 2012, reaching the laboratory within 12 hours of collection. Experiments were done at slightly different times of the year to coincide with the recruitment peak of each area. Average SST during the month prior to collection was $14.1{ }^{\circ} \mathrm{C}$ in Brittany and $13.3^{\circ} \mathrm{C}$ in Northern Portugal (Aqua MODIS SST, NASA). The same protocol and experimental conditions were used for both populations. 


\subsection{Experimental design}

Immediately upon arrival, each individual was placed in $0.5 \mathrm{~L}$ individual tanks with 0.2 $\mu \mathrm{m}$ filtered seawater (FSW) and aeration at $15{ }^{\circ} \mathrm{C}$ for 5 days of acclimation, so they could recover from eventual stress caused by collection and transportation. This temperature close to the conditions during the month of collection and small sporophytes and other microscopic forms of both species grow efficiently at $15{ }^{\circ} \mathrm{C}$ (Izquierdo et al., 2002; Norton, 1977; Pereira et al., 2011). These conditions were also used as control during the experiment. Throughout the acclimation and experimental periods, sporophytes were exposed to a $12 \mathrm{~h}$ day photoperiod, with a photon flux density of $40 \mu \mathrm{mol} \mathrm{m} \mathrm{m}^{-2} \mathrm{~s}^{-1}$ (Bruhn \& Gerard 1996; Izquierdo et al., 2002). Seawater was changed every two days during the acclimation period. During the heat shock experiment this was done every day after exposure, to make sure individuals were not exposed to metabolites, as tidal flow would quickly wash them away.

Temperature tolerance of young sporophytes (5 replicates) was tested for a series of sequential 1 hour exposures to one of five temperature treatments; $22.5,25,27.5$ or $30^{\circ} \mathrm{C}$. Unnaturally rapid warming was avoided by sequential transfer at each temperature, in a $30 \mathrm{~min}$ ramp, until the target temperature was reached. Exposure to the target temperature was for 1 hour. Afterwards, individuals were directly transferred back to the control temperature $\left(15^{\circ} \mathrm{C}\right)$ to simulate the returning tide, and remained at the control temperature till a $24 \mathrm{~h}$ cycle was complete. This procedure was repeated for 4 cycles. Measurements were repeatedly performed on the same individual and each was daily exposed to the same target temperature.

\subsection{Photosynthetic yield determination}

Photosynthetic activity is considered to be one of the most heat sensitive cellular processes, both by damage to the oxygen-evolving complex in PS II, damage and rapid turnover of the D1 protein, and by impairment of recovery processes by reactive oxygen species. As such, in vivo, the efficiency of reaction center functioning (controlling electron flux for 
downstream processes) represents a balance between damage and repair (Allakhverdiev et al., 2008). Initial values of chlorophyll maximum quantum yield (Fv/Fm) were measured for each individual (5 replicates per treatment) under control conditions. All Fv/Fm measurements were made with a portable chlorophyll fluorometer (Junior-PAM, Walz, Germany). Individuals were dark incubated for 5 minutes, after which Fv/Fm measurements were made on two different areas, in the center of the blade of each individual's. The mean of the two values was used in downstream analyses. Because small intrinsic differences in population- and/or locationspecific Fv/Fm values can obscure subsequent statistical comparisons between species and/or populations, all Fv/Fm data were normalized as a proportion of the initial values (adjusted mean=1). Initial $\mathrm{Fv} / \mathrm{Fm}$ values were above 0.7 to make sure the conditions used were not stressful.

During each of 4 consecutive $24 \mathrm{~h}$ cycles, individuals were exposed to heat shock for one hour at the target temperature, immediately after which Fv/Fm was measured. Individuals were then returned to the control temperature $\left(15^{\circ} \mathrm{C}\right)$ for recovery and $\mathrm{Fv} / \mathrm{Fm}$ was measured again after $24 \mathrm{~h}$ to assess recovery. Controls remained at $15 \stackrel{\circ}{ } \mathrm{C}$ throughout each cycle, but otherwise were manipulated in same way as the other treatments. The same individuals were used throughout the experiment and were always exposed to the same target temperature.

\subsection{Growth measurements}

Individual growth was expressed as relative change in blade area determined from photographs taken at the beginning of the experiment, after the acclimation period, and by the end of the 4 heat shock cycles. Tissue death was considered as negative growth. The software GIMP (GNU Image Manipulation Program) 2.6.6 was used for these measurements. 


\subsection{Statistical analysis}

PERMANOVA assesses differences in distribution, which may be caused by differences in means, in dispersion or both. PERMDISP focuses only on dispersion, complementing the PERMANOVA results. Both PERMANOVA and PERMDISP routines (Anderson et al., 2008) were used to analyze the data. Maximum quantum yield was compared between species and temperatures for each location. Growth data was compared for the two species exposed at the different temperatures. No direct statistically comparisons between French and Portuguese experiments were performed because these were done in different months of different years.

\section{Results}

The maximum quantum yield of photosystem II (Fv/Fm) of recruits collected in Brittany (France) varied between species, temperature and time (PERMANOVA, time ${ }^{*}$ species * temperature, $\mathrm{p}<0.0001$ ). At the control temperature, $15{ }^{\circ} \mathrm{C}$, no significant difference was observed through time for either species (Fig. 1). At $22.5^{\circ} \mathrm{C}$, although significant but rather small differences were observed through time, for both species, within the temperature treatment, there was no significant difference at each time point between $22.5^{\circ} \mathrm{C}$ and the control. Exposure to higher temperatures $\left(25\right.$ and $\left.27.5^{\circ} \mathrm{C}\right)$ caused significant initial decreases in Fv/Fm in L. ochroleuca following stress exposure. However, recovery was complete within each $24 \mathrm{~h}$ cycle. Thus, sublethal temperature stress in the Brittany L. ochroleuca population caused reversible reductions in $\mathrm{Fv} / \mathrm{Fm}$ (photoprotection of PSII). However, at $30{ }^{\circ} \mathrm{C}, \mathrm{Fv} / \mathrm{Fm}$ declined following each consecutive stress cycle, indicating a breakdown of thermal resilience. Nevertheless, at the end of the experiment all L. ochroleuca individuals were still alive. A rather different strategy was seen in S. polyschides from Brittany, where almost no effect of temperature on $\mathrm{Fv} / \mathrm{Fm}$ was observed between 15 and $27^{\circ} \mathrm{C}$ (Fig. 1), but where resilience collapsed after repeated exposure to $30^{\circ} \mathrm{C}$. By the end of the $4^{\text {th }}$ cycle no chlorophyll fluorescence could be detected for any individual, and no recovery was observed by the end of 
the experiment. As the threshold temperature tolerance was approached, individual variance clearly increased relative to that under control conditions (Fig. 1).

Kelp recruits from the French populations showed no significant interspecific differences in relative growth rates. Growth rates were, however, significantly affected by temperature (PERMANOVA, temperature, $p=0.0028$ ), being reduced as temperature increased to $27.5^{\circ} \mathrm{C}$ for L. ochroleuca, and to $30{ }^{\circ} \mathrm{C}$ for both species. At higher temperatures growth was surpassed by necrosis, resulting in size decrease (Fig. 2).

Fv/Fm of recruits from Portugal varied significantly over time between species and temperatures (PERMANOVA, Time*Species*Temperature, $p<0.0001$, Fig. 3). Data from the 15 ${ }^{\circ} \mathrm{C}$ treatment shows that L. ochroleuca and S. polyschides responded similarly to culture conditions, although the variations in $\mathrm{Fv} / \mathrm{Fm}$ over time and between individuals were greater than observed for the Brittany populations. Significant differences between post-stress and recovery points were not observed during exposure to either $22.5,25^{\circ} \mathrm{C}$ or $27.5^{\circ} \mathrm{C}$. Exposure of L. ochroleuca to $30{ }^{\circ} \mathrm{C}$ revealed a clearly greater resilience in the Portuguese compared to the Brittany population (c.f. Figs 1 and 3). Although photoinhibition increased with consecutive heat-shock cycles, recovery of $\mathrm{Fv} / \mathrm{Fm}$ to control levels occurred within $24 \mathrm{~h}$ after each exposure, indicating resilience to this level of thermal stress, as opposed to the population from Brittany. In contrast, Portuguese S. polyschides was even more affected by repeated exposure to $30{ }^{\circ} \mathrm{C}$. At this temperature, no resilience was observed and cumulative damage resulted in the death of all individuals by the $3^{\text {rd }}$ heat shock cycle (Fig. 3).

Relative growth of kelp recruits from Portugal varied significantly with species and temperature (PERMANOVA, species * temperature $p<0.0001$, Fig. 2). Growth rate shows a tendency to decrease with increasing temperature for both species, but this difference was significant only for S. polyschides, which showed a more pronounced trend. Relative growth differed significantly between species at $30^{\circ} \mathrm{C}$ only. 


\section{Discussion}

In this study we report lethal temperature limits and sub-lethal temperature effects for recruits of the two southernmost forest-forming kelp species in the northeastern Atlantic: $L$. ochroleuca and S. polyschides. We also show differences between populations of each species taken from southern and northern regions where they co-occur, with evidence that $L$. ochroleuca potentially exhibits greater thermal resilience near the southern edge of its range, which might indicate some adaptation to local conditions. Such phenotypic plasticity has been reported for S. polyschides (Biskup et al., 2014) and other kelp species, such as Laminaria digitata (Delebecq et al., 2012), Saccharina japonica (Pang et al., 2007) and Ecklonia radiata (Staehr \& Wernberg, 2009; Wing et al., 2007). Previous studies, based on constant growth temperature, reported that both species have a similar upper temperature limit of $23-25^{\circ} \mathrm{C}$ (Lüning, 1990; Norton, 1977). These limits were, however, determined by exposure to a constant growth temperature, and nothing was known about the impact of the rapid and consecutive temperature rise they are often exposed to in tidal pools, a common habitat in Portugal. Because the species occupy similar areas on the shore, it was expected that their responses would be similar. While water temperature in Northern Portugal is usually about 15 ${ }^{\circ} \mathrm{C}$, in tidal pools it may reach $20^{\circ} \mathrm{C}$ on warmer summer days and blades may be subjected to temperatures as high as $30{ }^{\circ} \mathrm{C}$ near the surface (Engelen et al., 2008). Both species showed resilience to relatively short exposures to temperatures above their reported $23-25{ }^{\circ} \mathrm{C}$ survival limit (Lüning, 1990; Norton, 1977). Although S. polyschides showed no significant response when exposed to up to $27.5^{\circ} \mathrm{C}$, when subjected to $30{ }^{\circ} \mathrm{C}$ a threshold seems to have been met as individuals were significantly damaged and died. In contrast, L. ochroleuca appeared more resistant to extreme temperatures; individuals from Brittany were damaged by $30{ }^{\circ} \mathrm{C}$ exposure but were still alive by the end of the experiment and individuals from Northern Portugal were even more resistant, showing total resilience. Still, temperature increase caused a tendency for blade elongation to decrease and at higher temperatures necrosis surpassed growth. This also 
happened for S. polyschides from both locations. While previous work (Biskup et al., 2014) reported a higher physiological plasticity of S. polyschides when compared to L. ochroleuca, consecutive exposure to high temperatures indicates that such disparate responses are mainly a matter of strategy, most likely associated with their distinct life history. L. ochroleuca, as a perennial species, benefits more from photo protective mechanisms, while for the opportunistic annual, S. polyschides, strategies for faster growth may be selected. Although $S$. polyschides is able to recruit in tidal pools, only few individuals can be found in the summer and the main kelp species occupying such areas is L. ochroleuca (personal observations; Barradas et al., 2011). The response of L. ochroleuca to short high temperature exposure suggests that its resilience provides an advantage to colonize such shallower areas. The inability of S. polyschides to cope with daily short exposure to $30^{\circ} \mathrm{C}$ may offer an explanation as to why these are found in tidal pools in such low number and there they do not reach similar dimensions to L. ochroleuca nor to those attained by other S. polyschides in the high subtidal (personal observations).

Responses to change in environmental conditions are reported to be largely mandated by an individual's history (Lüning, 1990). Although no significant difference in Fv/Fm between sites can be asserted for $S$. polyschides, the response of $L$. ochroleuca varied between sites at $30{ }^{\circ} \mathrm{C}$. While $L$. ochroleuca from Portugal exposed to $30{ }^{\circ} \mathrm{C}$ suffered necrosis, individuals from Brittany showed significant blade loss at temperatures above $27.5^{\circ} \mathrm{C}$, an important difference between populations. Although blade elongation is not an expression of meristematic activity, this balance between growth and necrosis is important for population persistence, particularly since an individual's spore production depends on blade length. Our finding on differences in responses to temperature between populations of $L$. ochroleuca does not match other studies on Laminaria $s p$, where the effect of temperature on growth and survival didn't vary significantly along a latitudinal range (Bolton and Lüning, 1982; Kain, 1967). Such variation has, however, been observed for other kelp species (Liu and Pang, 2010). 
Our results suggest that, in the near future, temperature will most likely not be a limiting factor for either species in the high subtidal, at least in the moderately exposed shores where they occur and where water mixing prevents strong thermal stratification at the surface. However, in tidal pools, a temperature increase might lead to higher apical blade loss and an increase in mortality rates. Moreover, climate change is accompanied by environmental changes other than temperature increase (Deysher and Dean, 1986; Han and Kain, 1996; Fortes and Lüning, 1980; Müller et al., 2009) which may impair local persistence before temperature increases enough to hamper recruit survival in tidal pools. Nevertheless, our results show that temperature responses can explain subtle differences in the upper distribution of these kelp species and variation between populations along the distributional range.

\section{Acknowledgements}

We thank the Station Biologique de Roscoff's diving team for collecting the recruits and sending them to our lab in Portugal. This was made possible thanks to the ASSEMBLE (ASSociation of European Marine Biological Laboratories) grant agreement no. 227799, which allowed accessing this facility remotely. Tania R. Pereira and Aschwin H. Engelen were supported by fellowships from the Portuguese Science and Technology Foundation (FCT). The research was supported by FCT projects PTDC/AAC-CLI/109108/2008 and EXCL/AAGGLO/0661/2012. We thank Márcio Coelho for his help on preliminary experiments.

\section{References}

Allakhverdiev, S.I., Kreslavski, V.D., Klimov, V.V., Los, D.A., Carpentier, R. and Mohanty, P. (2008) Heat stress: an overview of molecular responses in photosynthesis. Photosynth res.

98: $541-550$

Anderson, M.J., Gorley, R.N. and Clarke, K.R. (2008) PERMANOVA+ for PRIMER. Guide to software and statistical methods. PRIMER-E Ltd., Plymouth, UK. 214pp 
Barradas, A., Alberto, F., Engelen, A.H. and Serrão, E. (2011) Fast sporophyte replacement after removal suggests bank of latent microscopic stages of Laminaria ochroleuca (Phaeophyceae) in tide pools in northern Portugal. Cah Biol Mar. 52: 435-439

Beaugrand, G. and Reid, P. (2003) Long-term changes in phytoplankton, zooplankton and salmon related to climate. Glob change biol. 9: 801-817

Birkett, D.A., Maggs, C.A., Dring, M.J. and Boaden, P.J.S. (1998) Infralitoral reef biotopes with kelp species. Vol. VII

Bolton, J.J. and Lüning, K. (1982) Optimal growth and maximal survival temperatures of Atlantic Laminaria species (Phaeophyta) in culture. Mar Biol. 66: 89-94

Braud, J.P. (1974) Etude de quelques paramètres ecologiques, biologiques et biochimiques chez une Phéophycée de côtes bretonnes. PhD thesis. Université d'Aix Marseille II. 99pp

Bruno, J.F., Stachowicz, J.J. and Bertness, M.D. (2003) Inclusion of facilitation into ecological theory. Trends Ecol Evol. 18 (3): 119-125.

Cheung, W.W.L., Lam, V.W.Y., Sarmiento, J.L., Kearney, K., Watson, R. and Pauly, D. (2009) Projecting global marine biodiversity impacts under climate change scenarios. Fish and Fish. 10(3): $235-251$

Deysher, L.E. and Dean, T.A. (1986) Interactive effects of light and temperature on sporophyte production in the giant kelp Macrocystis pyrifera. Mar Biol. 93: 17-20

Engelen A.H., Espirito-Santo C., Simões T., Monteiro C., Serrão E.A., Pearson G.A. and Santos R.O.P. (2008). Periodicity of propagule expulsion and settlement in the competing native and invasive brown seaweeds, Cystoseira humilis and Sargassum muticum (Phaeophyta). European Journal of Phycology,43: 275 - 282

Fortes, M.D. and Lüning, K. (1980) Growth rates of North Sea macroalgae in relation to temperature, irradiance and photoperiod. Helgol meeresunters. 34: 15-29 
Franco, A.M.A., Hill, J.K., Kitschke, C., Collingham, Y.C., Roy, D.B., Fox, R., Huntley, B. and Thomas, C.D. (2006) Impacts of climate warming and habitat loss on extinctions at species's low-latitude range boundaries. Glob Change Biol. 12: 1545-1553

Guo, Q., Taper, M., Schoenberger, M. and Brandle, J. (2005) Spatial-temporal population dynamics across species range: from centre to margin. Oikos. 108: 47-57

Hampe, A. and Petit, R.J. (2005) Conserving biodiversity under climate change: the rear edge matters, Ecol Lett. 8: 461-467.

Han, T. and Kain, J.M. (1996) Effects of photon irradiance and photoperiod on young sporophytes of four species of Laminariales. Eur J Phycol. 31(3): 233-240

Harley, C.D.G., Hughes, A.R., Hultgren, K.M., Miner, B.G., Sorte, C.J.B., Thornber, C.S., Rodriguez, L.F., Tomanek, L. and Williams, S.L. (2006) The impacts of climate change in coastal marine systems. Ecol Lett. 9(2): 228-241

Helmuth, B., Harley, C.D.G., Halpin, P.M., O'Donnell, M., Hofmann, G.E. and Blachette, C.A. (2002) Climate change and latitudinal patterns of intertidal thermal stress. Science. 298: 1015-1017

Hiscock, K., Southward, A., Tittley, I. and Hawkins, S. (2004) Effects on changing temperature on benthic marine life in Britain and Ireland. Aquat Conserv. 14 (4): 333-362

IPCC (Intergovernmental Panel on Climate Change; core writing team: Pachauri, R.K. and Reisinger, A. eds) (2007) Climate change 2007: synthesis report. Contribution of Working Groups I, II ad III to the $4^{\text {th }}$ assessment report of the Intergovernmental Panel on Climate Change. IPCC, Geneva. pp104

Izquierdo, J.L., Pérez-Ruzafa, I.M. and Gallardo, T. (2002) Effect of temperature and photon fluence rate on gametophytes and young sporophytes of Laminaria ochroleuca Pylaie. Helgoland Mar Res. 55: 285-292.

Kain, J.M. (1967) Populations of Laminaria hyperborea at various latitudes. Helgoland Mar Res. 15: $489-499$ 
Kelly, A.E. and Goulden, M.L. (2000) Rapid shifts in plant distribution with recent climate change. PNAS. 105(33): 11823-11826

Lima, F.P. and Weathey, D.S. (2012) Three decades of high-resolution coastal sea surface temperatures reveal more than warming. Nat Commun. DOI: 10.1038/ncomms1713

Ling, S.D., Johnson, C.R., Frusher, S.D. and Ridgway, K.R. (2009) Overfishing reduces resilience in kelp beds to climate-driven catastrophic phase shift. PNAS. 106(52): 22341-22345

Liu, F. and Pang, S.J. (2010) Performance of growth, photochemical efficiency, and stress tolerance of young sporophytes from seven populations of Saccharina japonica (Phaeophyta) under short-term heat stress. J. Appl Phycol. 22(2): 221-229

Lüning, K. (1990) Seaweeds. Their Environment, Biogeography and Ecophysiology. John Wiley \& Sons. Inc. 527pp

Martínez, E.A. (1999) Latitudinal differences in thermal tolerance among microscopic sporophytes of the kelp Lessonia nigrescens (Phaeophyta: Laminariales). Pac Sci. 53(1): 7481

Mieszkowska, N., Kendall, M.A., Hawkins, S.J., Leaper, R., Williamson, P., HardmanMountford, N.J. and Southward, A.J. (2006) Changes in the range of some common rocky shore species in Britain - A response to climate change? Hydrobiologia 555: 241-251

Müller, R., Laepple, T., Bartsch, I. and Wiencke, C. (2009) Impact of oceanic warming on the distribution of seaweeds in polar and cold-temperate waters. Bot Mar. 52: 617-638.

Nicastro, K.R., Zardi, G.I., Teixeira, S., Neiva, J., Serrão, E.A. and Pearson G.A. (2013) Shift happens: trailing edge contraction associated with recent warming trends threatens a distinct genetic lineage in the marine macroalgae Fucus vesiculosus. BMC Biol. 11:6

Norton, P.A. (1977) Experiments on the factors influencing the geographical distribution of Saccorhiza polyschides and Saccorhiza dermatodea. New Phytol. 78: 625-635

Pang, S.J., Jin, Z.H., Sun, J.Z. and Gao, S.Q. (2007) Temperature tolerance of young sporophytes from two populations of Laminaria japonica revealed by chlorophyll fluorescence 
measurements and short-term growth and survival performance in tank culture. Aquaculture. 262: 493-503

Pehlke, C. and Bartsch, I. (2008) Changes in the depth distribution and biomass of sublittoral seaweeds in Helgoland (North Sea) between 1970 and 2005. Clim Res. 37: 135-147

Pereira, T.R., Engelen, A.H., Pearson, G.A., Serrão, E.A., Destombe, C. and Valero, M. (2011) Temperature effects on the microscopic haploid stage development of Laminaria ochroleuca and Saccorhiza polyschides, kelps with contrasting life histories. Cah Biol Mar. 52: 395-403

Sabatés, A., Martín, P., Lloret, J. and Raya, V. (2006) Sea warming and fish distribution: the case of the small pelagic fish, Sardinella aurita, in the western Mediterranean. Glob Change Biol. 12: 2209-2219

Tittley, I. and Neto, A.I. (2000) A provisional classification of algal-characterized rocky shore biotopes in the Azores. Hydrobiologia. 440: 19-25

tom Dieck, I. (1993) Temperature tolerance and survival in darkness of kelp gametophytes (Laminariales, Phaeophyta): ecological and biogeographical implications. Mar Ecol Prog Ser. 100: $253-264$

Van den Hoek, C. (1982) The distribution of benthic marine algae in relation to the temperature regulation of their life histories. Biol J Linn Soc. 18: 81-144

Wernberg, T., Thomsen, M.S., Tuya, F., Kendrick, G.A., Staehr, P.A. and Toohey, B.D. (2010) Decreasing resilience of kelp beds along a latitudinal temperature gradient: potential implications for a warmer future. Ecol Lett. 13: 685-694.

Zippay, M.L. and Hofmann, G.E. (2010) Physiological tolerances across latitudes: thermal sensitivity of larval marine snails (Nucella spp). Mar Biol. 157(4): 707-714 

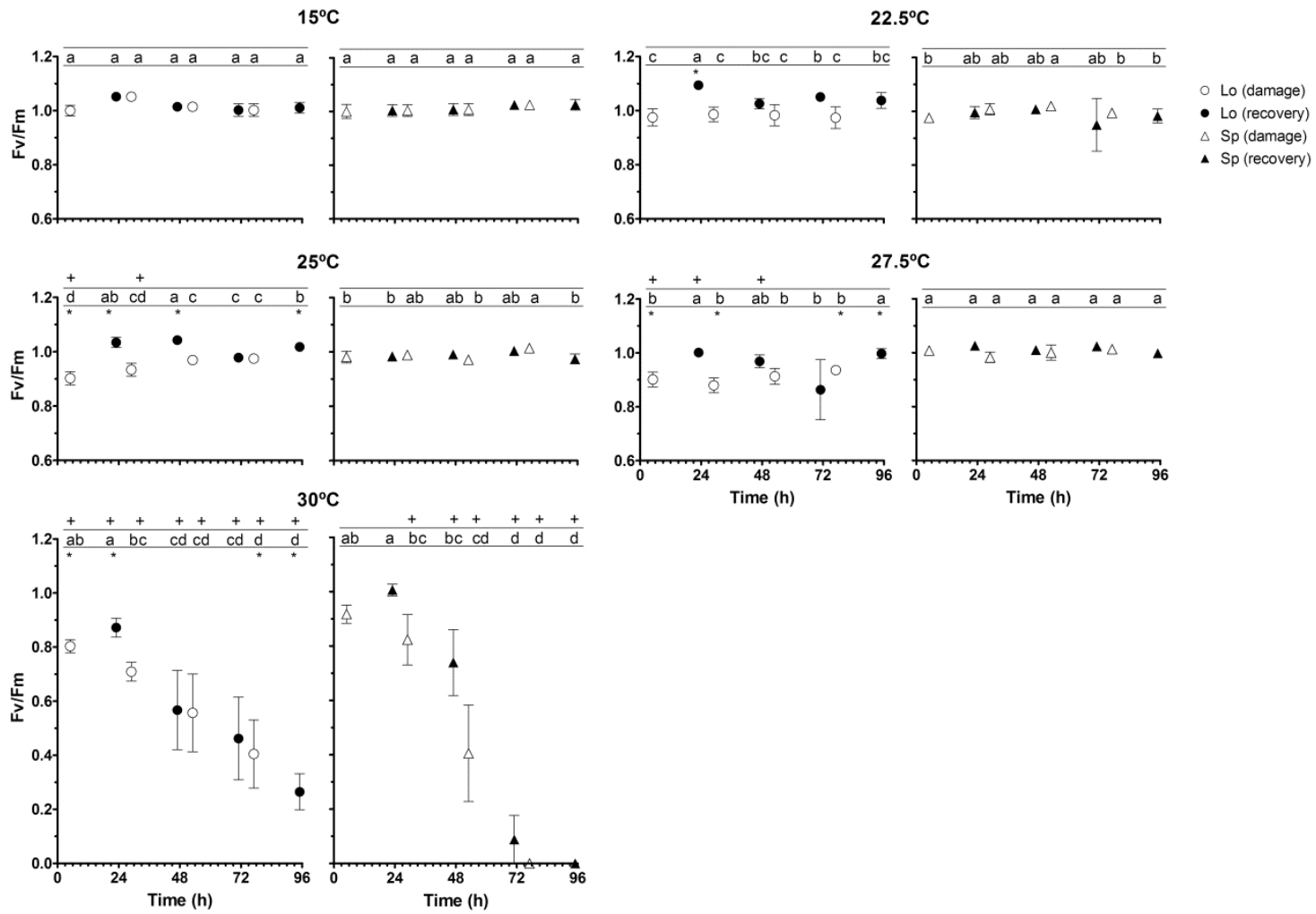

Figure 1 
Fig.1: Fv/Fm variations of Laminaria ochroleuca (left, circles) and Saccorhiza polyschides (right, triangles) from Northern Brittany, France, in response to exposure to repeated 1 hour temperature elevation. Error bars represent standard error $(n=5)$. Open symbols indicate measurements post-stress. Closed symbols refer to measurements after the recovery period. + indicates a significant difference from the control $\left(15^{\circ} \mathrm{C}\right) .{ }^{*}$ indicates a significant difference between the two species. Different letters were attributed, per species and temperature, to significantly different means. 

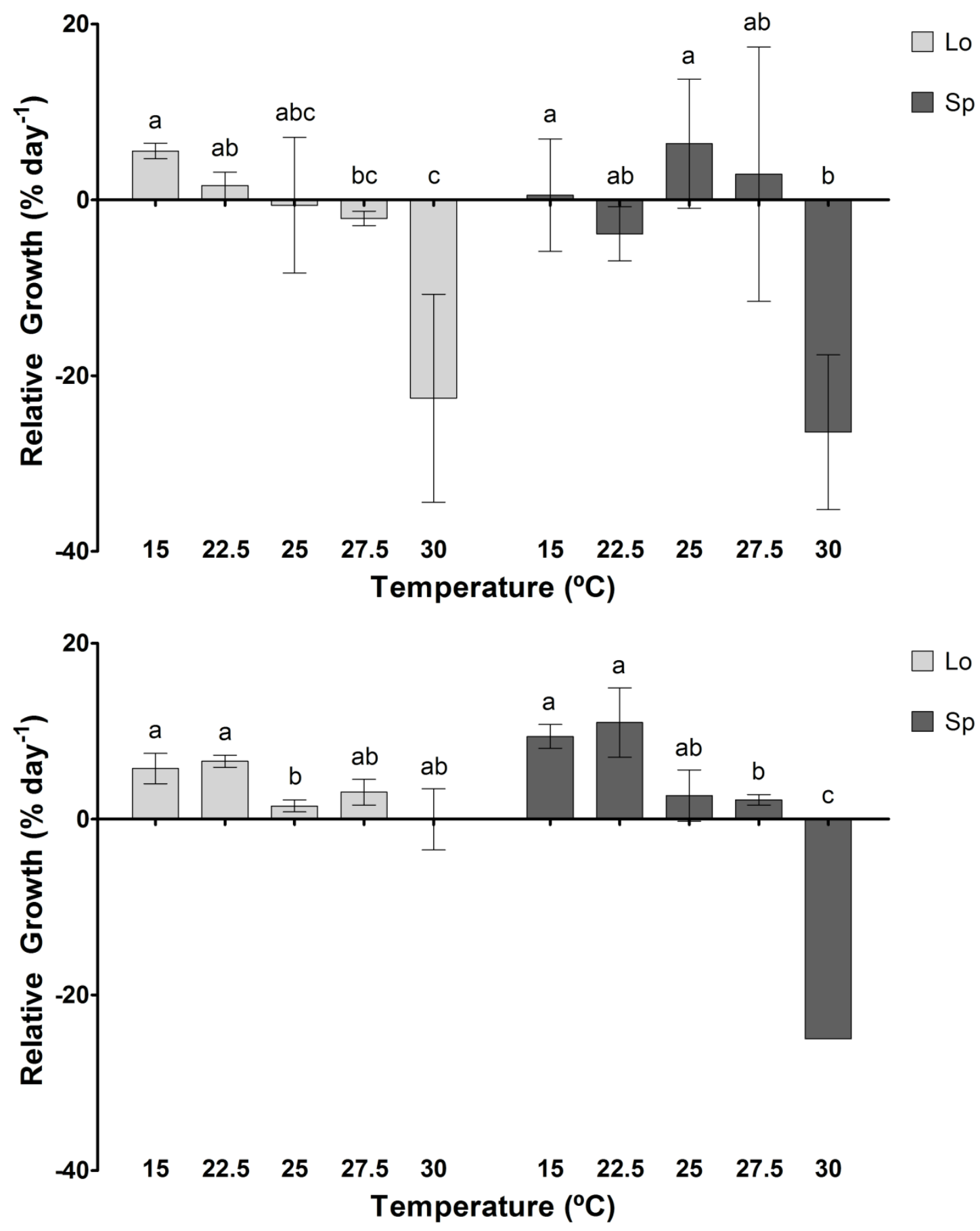

Figure 2 
Fig. 2: Mean relative blade area growth rate $(n=5)$ of $L$. ochroleuca (Lo) and S. polyschides ( $\mathrm{Sp}$ ) from Brittany, France (top) and Northern Portugal (bottom), cultivated at $15{ }^{\circ} \mathrm{C}$ with daily recurrent exposures of one hour to $15,22.5,25,27.5$ and $30{ }^{\circ} \mathrm{C}$. Error bars represent standard error. Different letters were assigned, per species, to points with significantly different means $(p<0.05)$. No significant difference was observed between species at identical temperature treatments. 

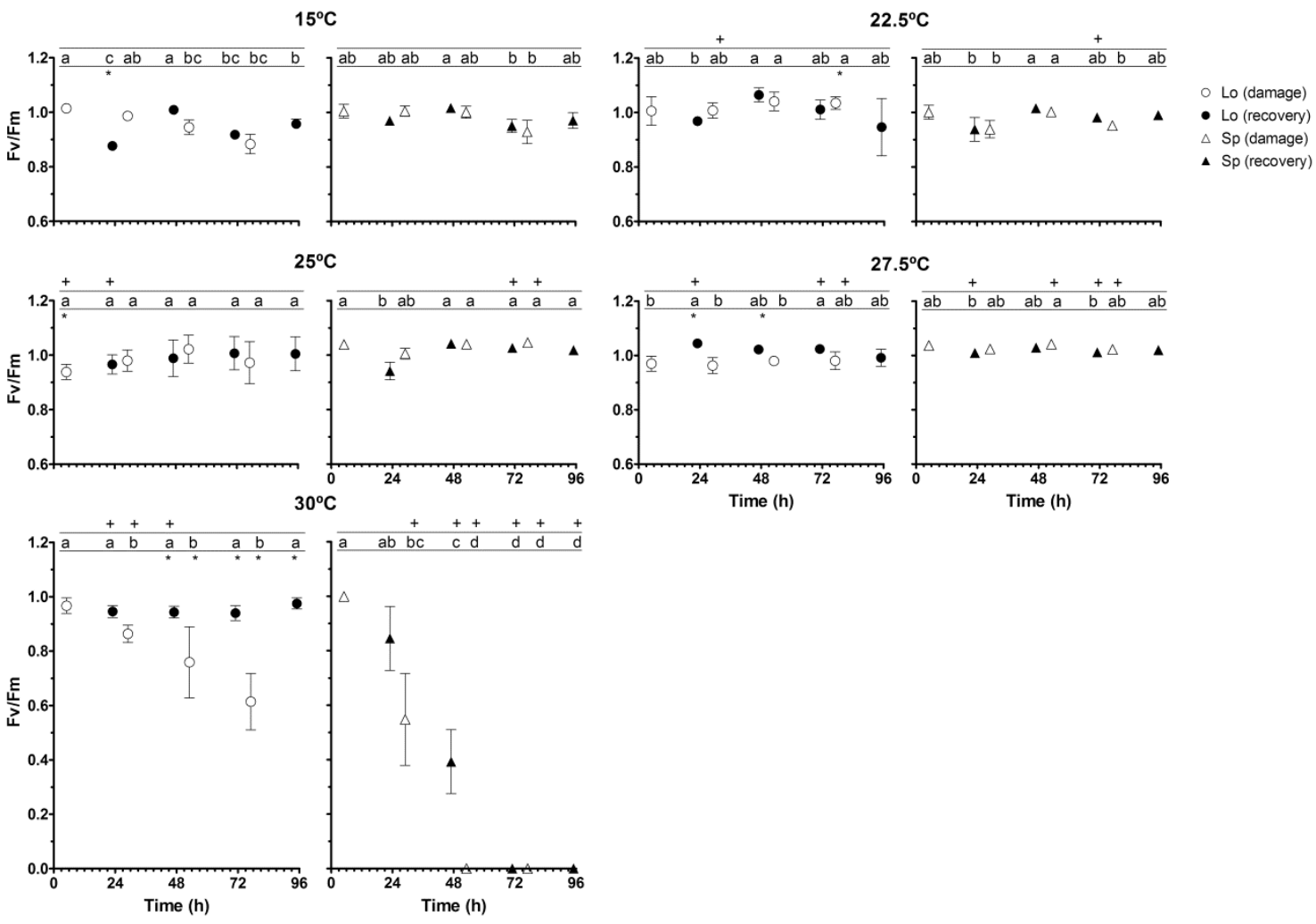

Figure 3 
Fig.3: Fv/Fm variation with repeated exposure to high temperature in Laminaria ochroleuca (left, circles) and Saccorhiza polyschides (right, triangles) from Northern Portugal. Error bars represent standard error $(n=5)$. Open symbols indicate measurements after the heat shock. Closed symbols refer to measurements after the recovery period. + indicates a significant difference from the control $\left(15^{\circ} \mathrm{C}\right) .{ }^{*}$ indicates a significant difference between the two species. Different letters were attributed, per species, within each temperature, to significantly different points. 